\title{
Frequency and severity of globus pharyngeus symptoms in patients undergoing thyroidectomy: a pre-post short term cross-sectional study
}

\author{
Fabrizio Consorti", Rosaria Mancuso, Valentina Mingarelli, Eugenio Pretore and Alfredo Antonaci
}

\begin{abstract}
Background: Globus pharyngeus is a sensation of a lump or foreign body in the throat, sometimes associated with thyroid diseases and surgery. Previous studies investigated this condition with contradictory results, mainly because not standardized instruments of measure were used. The aim of this study was to evaluate the prevalence and severity of globus pattern symptoms in a population of patients three months after a thyroidectomy, and the reduction or increase of pre-existing symptoms or the onset of new symptoms.

Methods: Ninety-five patients (65 women, 30 men, mean age $56.03 \pm 12.45$ ) were assessed for globus pattern symptoms before and three months after thyroid surgery (72 patients: benign goiter, 23 patients: papillary cancer). The Glasgow-Edinburgh Throat Scale (GETS) was translated into Italian and used as a validated instrument of measure of the severity of globus pattern symptoms.

Results: The Italian version of the GETS was reliable (Cronbach alpha $=0.85)$ and valid. Normative data were used to classify patients into 4 groups of severity. A significant decrease of the mean GETS score was observed at the postoperative assessment (13.02 \pm 11.84 vs $8.00 \pm 11.26 ; p<0.01)$, but beside symptomatic patients who improved we could observe also two other significant groups of patients: asymptomatic patients who developed symptoms and symptomatic patients who remained symptomatic.

Conclusions: The significant decrease of the mean GETS postoperative score was mainly due to the improvement of strongly symptomatic patients. Two other significant outcomes exist and further studies are needed to understand their pathophysiological mechanism.
\end{abstract}

Keywords: Globus pharyngeus, Thyroid surgery, Assessment of outcome

\section{Background}

Swallowing disorders are frequent in aged people [1], but they are underestimated both by patients and physicians [2], perhaps because their onset is often slow.

Swallowing is a complex motor reflex requiring coordination among the neurologic system, the oropharynx, and the esophagus. A number of disorders, both benign and malignant, can interfere with this process and globus pharyngeus is a common related symptom. It is defined as the feeling of a lump in the throat, it has uncertain origin and constitutes about $4 \%$ of all new ENT referrals [3]. According to Deary [4] 6\% of his

\footnotetext{
* Correspondence: fabrizio.consorti@uniroma1.it

Department of Surgical Sciences, University "Sapienza" of Rome, Viale del Policlinico, 00161 Roma, Italy
}

study group of 1158 women complained about globus and Thompson [5], in a community based study, reported that $45.6 \%$ of the general population had experienced globus sensation at some time in their lives. Globus was first described by Purcell in 1707 who coined the term globus hystericus, (globus originating from the Latin meaning "ball" and "hystericus" reflecting the supposed psychological component of the disorder). Traditionally patients presenting with globus symptoms were referred to psychiatrists and a study demonstrated that the these subjects were significantly higher on neuroticism and low on extra-version scales and have significantly elevated levels of psychological distress, including anxiety, low mood, and somatic concern when compared with the control subjects [4]. The disorder was renamed globus pharyngeus 
in 1968 by Malcomson [6] and more recently it has been defined as a persistent or intermittent sensation of a lump or foreign body in the throat for at least 12 weeks with occurrence of the sensation between meals, absence of dysphagia and odynophagia, absence of pathological gastroesophageal reflux, achalasia, or other motility disorder with a recognized pathological basis (e.g., scleroderma of the oesophagus) [7]. Psychological and psychiatric characteristics could be relevant to the experienced discomfort but are unlikely to be etiologically significant. In fact, several potential organic causes for globus pharyngeus were supposed, such as lingual tonsillar hypertrophy, cervical osteophytes, iron deficiency anemia, temporomandibular joint disorder [7]. Laryngopharyngeal reflux [8], hypertensive upper esophageal sphincter [9] and autoimmune diseases [10] have been considered potential causes. Two recent reviews $[11,12]$ summarized the main current findings about globus.

The role of thyroid diseases has also been explored [13]. Goiter is often associated with globus like symptoms, but the exact mechanism is poorly understood, particularly in the absence of a significant retrosternal extension. Burns [14] found that one-third of patients with a thyroid mass complained of globus pattern symptoms. Moreover post-thyroidectomy patients may also complain of globus pattern symptoms, although these symptoms frequently settle with time $[15,16]$. According to Maung [17] thyroid surgery does not aggravate but rather improves preexisting globus pattern symptoms, while in the study of Wassermann [18] these symptoms increased after surgery. All of these studies relied on the mean value of a score and did not explicitly present data about the rate of asymptomatic patients developing globus pattern symptoms in the post-operative period. The aim of this study is to evaluate the prevalence and severity of globus pattern symptoms in a population of patients three months after thyroidectomy, as a result of reduction or increase of pre-existing symptoms or as the onset of a new set of symptoms.

\section{Methods}

In this cross-sectional longitudinal study, a clinical series of patients operated for thyroid disease were assessed to measure the prevalence and severity of globus symptoms, before and three months after surgery.

The survey was done at the department of Surgical Sciences, recruiting patients candidate to surgery for any thyroid disease from January 2013 to April 2014. Criteria of exclusion were substernal goiter, previous neck surgery, extracapsular cancer, history of gastro-esophageal reflux and poor linguistic skill. This last condition was set because of the use of an instrument of rating of globus symptoms based on a questionnaire in which a rather rich terminology is used. A poor understanding could have hampered the reliability of the assessment. Only patients who underwent a total thyroidectomy were considered.

From a series of 105 patients, 10 met the exclusion criteria, so 95 patients were considered. They were 65 women and 30 men, mean age $56.03 \pm 12.45$. Indications to surgery were multinodular goiter or cytologically suspected cancer and the final diagnoses were benign goiter in 72 patients and papillary cancer in 23 patiens. All patients routinely underwent pre and postoperative indirect laryngoscopy for vocal cords control and none of the considered patients had vocal cord palsy.

The Glasgow-Edinburgh Throat Scale (GETS) [19] was used to measure the presence and severity of globus symptoms. The GETS is a 10-items questionnaire, based on a 8 grade Likert scale, from 0 (absent) to 7 (unbearable). The total GETS score is computed summing the score of the 10 items, so the highest possible score is 70 . Each item explores a different symptom in the domain of globus pharyngeus. In its original form, the GETS showed a good reliability, with a Cronbach alpha value of 0.83 . Factor analysis revealed the presence of three subscales, grouping set of items: related to swallowing, related to globus sensation, related to painful throat. Two more items are present, whose score is not computed in the total GETS score but accounts for the somatic distress reaction to symptoms (SDR score: how much time do you spend thinking about your throat? At present, how annoying do you find your throat sensation?). We translated the 12 items into Italian and tested the instrument in a preliminary set of 30 patients, different from those recruited for the present study. This set was also used to train the two researchers in charge of doing the interviews. All the interviews in the study were done by one of the two trained researchers (RM or EP). All patients gave their verbal consent to the interview. The ethical committee of the department stated that ethical approval was not needed because the filled form of the interview was included in the medical record as a special part of the clinical history section.

\section{Statistical methods}

To define the study size, from previous literature $[13,14,16,18]$ we considered the hypothesis that about $50 \%$ of patients who were symptomatic before the operation would retain some symptoms, while $5 \%$ of asymptomatic patients will develop symptoms in the postoperative period. With an alpha error of $5 \%$ and a power of $90 \%$, the sample size needed to detect as significant the variation of the presence and severity of the symptoms in the postoperative period was constituted by 50 symptomatic and 15 asymptomatic patients. 
Table 1 Rotated component matrix of the loading factors for the $\mathbf{1 0}$ items of GETS

\begin{tabular}{|c|c|c|c|}
\hline \multirow[t]{2}{*}{ Items } & \multicolumn{3}{|c|}{ Component } \\
\hline & 1 & 2 & 3 \\
\hline Feeling of something stuck in the throat & .448 & .647 & .035 \\
\hline Pain in the throat & .141 & .075 & .905 \\
\hline Discomfort/irritation in the throat & .330 & .597 & .362 \\
\hline Difficulty in swallowing food & .841 & .133 & -.146 \\
\hline Swelling in the throat & -.076 & .724 & .192 \\
\hline Throat closing off & .658 & .494 & .187 \\
\hline Catarrh down throat & .072 & .607 & -.254 \\
\hline Can't empty throat when swallowing & .760 & .103 & .291 \\
\hline Want to swallow all the time & .458 & .505 & .149 \\
\hline Food sticking when swallowing & .874 & .058 & .140 \\
\hline \multicolumn{4}{|c|}{$\begin{array}{l}\text { Component 1: symptoms related to swallowing; Component 2: symptoms } \\
\text { related to globus sensation; Component 3: pain. } \\
\text { Factor loadings represent how much a factor explains a variable in factor } \\
\text { analysis. It is accepted that a value higher than } .50 \text { indicates that the answer } \\
\text { to that particular item is mainly influenced by that factor. Loadings }>.50 \text { are } \\
\text { highlighted in bold. }\end{array}$} \\
\hline
\end{tabular}

The re-validation of the Italian version of the GETS was performed with classical item analysis, computing the Cronbach alpha index. A principal component factor analysis was also performed, with varimax rotation and extracting components with an eigenvalue $>1$.

Differences in proportion were assessed by chi square test, differences in the GETS and SDR scores by Wilcoxon test for non-parametric data. All calculations were done with SPSS ${ }^{\text {mw }}$ ver.20 statistical software.

\section{Results}

Validation of the Italian version of the GETS and normative classification of the score

The Cronbach alpha value for the 10-items GETS scale was 0.85 and 0.92 for the two items on distress reaction. Factor analysis for the 10 items of the GETS demonstrated the same three sub-factors as in Deary's study [19] (Table 1).

To obtain an outcome more clinically oriented than a score without thresholds, we divided the distribution of the GETS score into five classes, setting thresholds at the $20^{\text {th }}$ (range: $0 \div 2$ points), $40^{\text {th }}$ (range: $3 \div 8$ points), $60^{\text {th }}$ (range: $9 \div 12$ points), $80^{\text {th }}$ (range: $9 \div 20$ points) and over the $80^{\text {th }}$ centile ( $>20$ points) of the preoperative distribution of scores. This method of classification, developed for educational research, proved to be useful in analyzing the distribution of a rank of scores [20]. According to these thresholds, we classified patients as asymptomatic, mildly symptomatic, symptomatic $\left(3^{\text {rd }}\right.$ and $4^{\text {th }}$ class together), strongly symptomatic .

Table 2 reports the synthetic data of preoperative assessment for the 12 items.

\section{Pre-postoperative comparison of GETS and SDR scores}

The mean GETS preoperative score was $13.02 \pm 11.84$ (C.I. $95 \%$ : $10.64 \div 15.40$, $\min =0$; $\max =57$ ), the mean postoperative score was $8.00 \pm 11.26$ (C.I. $95 \%$ : $6.01 \div 11.59$, $\min =0 ; \max =51)$. This difference was significant at Wilcoxon rank sum test $(\mathrm{p}=0.005)$. According to the classification of scores, $38.9 \%$ of patients in the postoperative period were asymptomatic (37 pts, GETS score $0 \div 2$ ), $23.1 \%$ were mildly symptomatic (22 pts, $3 \div 8$ ), $30.5 \%$ were symptomatic $(29 \mathrm{pts}, 9 \div 20)$ and $7.4 \%$ were strongly symptomatic (7 pts, $>20$ ) (Table 3 ). To describe the changes of the GETS score of patients from preoperative to postoperative assessment, we considered the possible main transitions: symptomatic patients who became asymptomatic or less symptomatic and vice versa. Table 4 summarizes these transitions.

The pre and postoperative mean score of the two items for somatic distress reaction was respectively $3.44 \pm 4.28$ (C.I. $95 \%$ : $1.06 \div 5.82$, $\min 0$, $\max 14$ ) and $2.43 \pm 3.28$ (C.I. 95\%: $1.77 \div 3.09$, $\min 0$, $\max 13$ ). This difference was not statistically significant. Both the pre and postoperative distress scores were correlated with the GETS scores (correlation coefficient for preoperative scores: 0.50; for postoperative scores: 0.76 ).

\section{Discussion}

Our study confirmed that a relevant proportion of patients with thyroid disease, if carefully enquired with a standardized instrument, complains of globus pattern symptoms of moderate or strong severity (57.8\%). A

Table 2 Synthetic data for the 10 items of GETS and the 2 items on somatic distress reaction, preoperatively assessed on 95 patients

\begin{tabular}{|c|c|c|c|c|c|c|c|c|c|c|c|c|}
\hline & \multicolumn{10}{|c|}{ Glasgow-Edinburgh Throat Scale (GETS): 10 items } & \multicolumn{2}{|c|}{ Somatic distress reaction } \\
\hline & stuck & pain & irritation & $\begin{array}{l}\text { difficult } \\
\text { swallowing }\end{array}$ & swelling & closing off & catarrh & $\begin{array}{l}\text { can't } \\
\text { empty }\end{array}$ & $\begin{array}{l}\text { swallow } \\
\text { all time }\end{array}$ & $\begin{array}{l}\text { food } \\
\text { sticking }\end{array}$ & time & $\begin{array}{l}\text { find } \\
\text { annoying }\end{array}$ \\
\hline Mean score & 2.27 & .66 & 1.66 & .97 & 1.07 & 1.31 & 1.52 & 1.04 & 1.48 & 1.03 & 1.59 & 1.85 \\
\hline St.dev. & 1.98 & 1.26 & 2.00 & 1.63 & 1.80 & 2.06 & 2.13 & 1.66 & 2.21 & 1.76 & 2.18 & 2.24 \\
\hline N.of score 0 & 27 & 68 & 46 & 62 & 61 & 57 & 51 & 57 & 54 & 62 & 50 & 41 \\
\hline N.of score 7 & 3 & 1 & 2 & 1 & 2 & 3 & 6 & 1 & 6 & 1 & 6 & 7 \\
\hline
\end{tabular}

In bold the most frequent four symptoms. 
Table 3 Distribution of patients in the four classes of GETS score before and after the operation: number of patients (\%)

\begin{tabular}{lll}
\hline Class of GETS score & Preoperative & Postoperative \\
\hline Asymptomatic (0-2) & $20(21.1)$ & $37(38.9)$ \\
Mildly symptomatic (3-8) & $20(21.1)$ & $22(23.1)$ \\
Symptomatic (9-20) & $36(37.8)$ & $29(30.5)$ \\
Strongly symptomatic $(>20)$ & $19(20.0)$ & $7(7.5)$ \\
Total & $95(100)$ & $95(100)$ \\
\hline
\end{tabular}

chi square test: $p<0.01$.

second group declares mild symptoms (21.1\%) and only about $20 \%$ of patients are completely asymptomatic or just report faint feelings in the domain of globus. When the mean GETS score was considered, a significant decrease of the severity of symptoms was observed after thyroidectomy, but this decrease was mainly due to the improvement of strongly symptomatic patients (Table 3 ). When the change of the pre-postoperative GETS score of each patient was considered (Table 4), a group of patients appeared who were asymptomatic or mildly symptomatic at the preoperative assessment and whose severity of symptoms increased in the postoperative period $(12 / 95$ patients $=12.6 \%)$. Another larger group of patients $(26 / 95$ patients $=27.4 \%)$ were mildly o definitely symptomatic and maintained unchanged their symptoms while the largest group of symptomatic patients improved $(37 / 95$ patients $=38.9 \%)$. These data indicate that surgery improves the condition of patients with moderate or intense globus pattern symptoms, but may make symptoms appear in asymptomatic of weakly symptomatic patients.

These findings suggest that the pathophysiology of globus pattern symptoms may be different: in some cases connected with thyroid disease, in other cases with the effect of surgery itself. Finally, in some patients of this series, globus pattern symptoms remained unchanged and seemed to be independent both from thyroid disease and from thyroidectomy. An alternative interpretation for the group of patients who remained symptomatic is that thyroidectomy produced the same pathophysiological effect as the presence of an ill thyroid did before the operation.
Other studies enquired the relationship between thyroid surgery and globus pattern symptoms, but all of them had limits either in the representation of data or in the extent and method used to assess globus pattern symptoms. In a small scale study, Maung et al. [17] did not find any significant worsening of GETS score three and twelve months after surgery. Some of the items of the GETS showed instead an improvement. Unfortunately the authors did not provide the mean total GETS score nor the mean values for each item, so a comparison with our study is not possible. Burns et al. [ 14 ] in a series of 200 patients who underwent thyroidectomy found 58 patients $(29 \%)$ with preoperative globus symptoms, which reduced to 12 (6\%) 3-6 months after the operation. The authors used a visual-analogue scale graduated from 1 to 10 to let the patient self-assess the globus sensation as a whole. Wasserman et al. [18] reported instead an increase of globus sensation, from $57.6 \%$ to $75.8 \%$ of patients one week after thyroid surgery. The focus of their study was on the correlation of symptoms with the function of the internal branch of the superior laryngeal nerve (SLN), which brings sensitivity to the larynx, but they could not find any significant decrease in SLN functioning. Lombardi et al. [16] reported an increase in swallowing alterations after thyroidectomy. They measured the symptoms with an original questionnaire, reporting a very low preoperative score, a strong rise one week after surgery and a progressive decrease after one and three months. Unfortunately they questionnaire fully covered only the dimension of dysphagia and partly the dimension of globus sensation of the GETS. In a wide Italian multicentric study on postoperative complications in 14,943 operations on thyroid, dysphagia was the only symptom considered in the globus pattern domain and only in relation to SLN damage [21]. Finally, Smith-Hammond et al. reported a significant increase of dysphagia - measured with a standardized questionnaire - after spine surgery with anterior cervical approach [22], accessing the same anatomical space as in thyroid surgery.

The terms in which the globus symptoms are described by patients vary largely and this is why we preferably referred to a pattern of globus symptoms. To manage this variability, it is important to rely on a validated and

Table 4 Modification of the level of symptoms, according to GETS score, after the operation, stratified for the four classes of score

\begin{tabular}{lllll}
\hline Class of GETS preoperative score & Improved & Unchanged & Worsened & Total \\
\hline Asymptomatic (0-2) & $0(0)$ & $16(80)$ & $4(20)$ & $8(40)$ \\
Mildly symptomatic (3-8) & $4(20)$ & $8(40)$ & $100)$ & $0(0)$ \\
Symptomatic (9-20) & $21(58.3)$ & $15(41.7)$ & $0(0)$ & $36(100)$ \\
Strongly symptomatic (>20) & $16(84.2)$ & $3(15.8)$ & $19(100)$ \\
\hline
\end{tabular}

The considered outcome are: improved (moved to a lower class), unchanged, worsened (moved to a higher class). In each cell: number of patients (\%). chi square test: $p<0.01$. 
comprehensive instrument like the GETS. The Italian version of the GETS we used had a good reliability and the same factorial structure as the original one. Normative data on the general [23] and ENT population [4] are available and indicate that a significant proportion of people without any evident structural pathology has a score of 1 or 2 at one of the items of the GETS (up to $55.2 \%$ for "Catarrh down throat" in [23]). The four classes of score we proposed are coherent with the above mentioned normative data and are clinically oriented. The classification of patients allowed to uncover three different dynamics, which were otherwise obscured by the synthetic presentation of data only by the pre and postoperative means: symptomatic patients who improved their symptoms after surgery, asymptomatic patients who developed symptoms after surgery and patients whose symptoms seemed not to be influenced by surgery.

The main limit of this study is the short follow up interval, limited to three months. It is known that symptoms tend to resolve after one year [24]. Nevertheless, even if symptoms are temporary, it is important to know their frequency in order to make patients informed and aware. Another possible limitation is that each interview was made only by one of the two trained observers, even if they had reached a good inter-rater agreement during the testing phase. We did not assess in any formal way the presence of gastro-esophageal reflux apart from history taking, so we cannot exclude that some of the patients who remained symptomatic could have been suffering from an unknown reflux [25]. We did not correlate symptoms with smoking habit or with other possible risk factors for globus pattern symptoms, such as thyroid volume, since the goal of this study was to measure frequency and severity of pre e and postoperative symptoms in a population of patients operated for thyroid disease.

As a last remark, it is known that a repetitive strain injury of the paralaryngeal muscles can cause globus-like symptoms. This mechanism could be considered either in the event of preoperative or postoperative symptoms. In these cases, manual therapy proved to be effective in quickly relieving the symptoms $[26,27]$.

\section{Conclusion}

In conclusion, research on outcome after surgery must be supported by valid and reliable instruments, especially when outcomes related to symptoms and quality of life are addressed. We demonstrated three possible outcomes after thyroid surgery as to globus pattern symptoms and on this basis further studies are needed to understand the pathophysiological mechanisms leading to these outcomes.

\section{Competing interests}

The authors declare that they have no competing interests.

\section{Authors' contributions}

FC designed the research and wrote the draft of the article, RM and EP did the interviews, VM did statistical calculations, AA gave the final approval, all authors discussed the results and contributed to the interpretation and discussion of results. All authors were also involved as members of the surgical team. All authors read and approved the final manuscript.

Received: 25 October 2014 Accepted: 20 April 2015

Published online: 01 May 2015

\section{References}

1. Schindler JS, Kelly JH. Swallowing disorders in the elderly. Laryngoscope. 2002;112(4):589-602.

2. Tibbling L, Gustafsson B. Dysphagia and its consequences in the elderly. Dysphagia. 1991;6(4):200-2.

3. Moloy PJ, Charter R. The globus symptom. Arch Otolaryngol. 1982;108:740-4.

4. Deary IJ, Wilson JA, Kelly SW. Globus pharyngis, personality, and psychological distress in the general population. Psychosomatics. 1995:36(6):570-7

5. Thompson WG, Heaton KW. Heartburn and globus in healthy people. Can Med Assoc J. 1982;126:46-8.

6. Malcomson KG. Globus hystericus vel pharyngis (a recommaissance of proximal vagal modalities). J Laryngol Otol. 1968;82(3):219-30.

7. Cashman EC, Donnelly MJ. The natural history of globus pharyngeus. Int J Otolaryngol. 2010;Article ID 159630. doi:10.1155/2010/159630.

8. Fass R, Achem AS, Harding S, Mittal RK, Quigley E. Supra-Oesophageal manifestations of gastro- oesophageal reflux disease and the role of night-time gastro-Oesophageal reflux. Alim Pharmacol Ther. 2004:20(9):26-38.

9. Corso MJ, Pursnani KG, Mohiuddin MA, Gideon RM, Castell JA, Katzka DA, et al. Globus sensation is associated with hypertensive upper esophageal sphincter but not with gastroesophageal reflux. Dig Dis Sci. 1998;43(7):1513-7.

10. Masterson LM, Srouji IA, Musonda P, Scott DG. Autoimmune disease as a risk factor for globus pharyngeus: a cross-sectional epidemiological study. Clin Otolaryngol. 2011;36(1):24-9.

11. Mitchell S, Olaleye O, Weller M. Review: current trends in the diagnosis and management of globus pharyngeus. Int J Otolaryngol Head Neck Surg. 2012;1:57-62.

12. Lee BE, Kim GH. Globus pharyngeus: a review of its etiology, diagnosis and treatment. World J Gastroenterol. 2012;18(20):2462-71.

13. Marshall JN, Mcgann G, Cook JA, Taub N. A prospective controlled study of high-resolution thyroid ultrasound in patients with globus pharyngeus. Clin Otolaryngol Allied Sci. 1996;21(3):228-31.

14. Burns B, Timon C. Thyroid pathology and the globus symptom: are they related? A two year prospective trial. J Laryngol Otol. 2007;121:242-5.

15. Khalil HS. The diagnosis and management of globus: a perspective from the United Kingdom. Curr Opin Otolaryngol Head Neck Surg. 2008;16(6):516-20.

16. Lombardi CP, Raffaelli M, D'Alatri L, Marchese MR, Rigante M, Paludetti G. Voice and swallowing changes after thyroidectomy in patients without inferior laryngeal nerve injuries. Surgery. 2006;140(6):1026-32.

17. Maung KH, Hayworth D, Nix A, Atkin SL, England RJ. Thyroidectomy does not cause globus pattern symptoms. J Laryngol Otol. 2005;1 19:973-5.

18. Wasserman JM, Sundaram K, Alfonso AE, Rosenfeld RM, Har-El G. Determination of the function of the internal branch of the superior laryngeal nerve after thyroidectomy. Head Neck. 2008;30(1):21-7.

19. Deary IJ, Wilson JA, Harris MB, MacDougall G. Globus pharyngis: development of a symptom assessment scale. J Psychosom Res. 1995;39(2):203-13.

20. De Landshhere G. Empirical research in education. Paris: United Nations Educational, Scientific and Cultural Organization; 1982. p. 82-95.

21. Rosato L, Avenia N, Bernante P, De Palma M, Gulino G, Nasi PG, et al. Complications of thyroid surgery: analysis of a multicentric study on 14,934 patients operated on in Italy over 5 years. World J Surg. 2004;28(3):271-6.

22. Smith-Hammond CA, New KC, Pietrobon R, Curtis DJ, Scharver $\mathrm{CH}_{\text {, Turner }}$ DA. Prospective analysis of incidence and risk factors of dysphagia in spine surgery patients: comparison of anterior cervical, posterior cervical, and lumbar procedures. Spine. 2004;29(13):1441-6. 
23. Ali KH, Wilson JA. What is the severity of globus sensation in individuals who have never sought health care for it? J Laryngol Otol. 2007;121(9):865-8.

24. Lombardi CP, Raffaelli M, De Crea C. Long-term outcome of functional post-thyroidectomy voice and swallowing symptoms. Surgery. 2009;146(6):1174-81.

25. Cathcart RA, Steen N, Natesh BG, Ali KH, Wilson JA. Non-voice-related throat symptoms: comparative analysis of laryngopharyngeal reflux and globus pharyngeus scales. J Laryngol Otol. 2011;125(1):59-64.

26. Rubin JS, Lieberman J, Harris TM. Laryngeal manipulation. Otolaryngol Clin North Am. 2000;33(5):1017-34.

27. Mathieson L, Hirani SP, Epstein R, Baken RJ, Wood G, Rubin JS. Laryngeal manual therapy: a preliminary study to examine its treatment effects in the management of muscle tension dysphonia. J Voice. 2009;23(3):353-66.

\section{Submit your next manuscript to BioMed Central and take full advantage of:}

- Convenient online submission

- Thorough peer review

- No space constraints or color figure charges

- Immediate publication on acceptance

- Inclusion in PubMed, CAS, Scopus and Google Scholar

- Research which is freely available for redistribution 